\title{
BMJ Open Gender-specific and age-specific differences in unstable angina pectoris admissions: a population-based registry study in Finland
}

\author{
Ville Kytö,, ${ }^{1,2}$ Jussi Sipilä,, ${ }^{3,4}$ Päivi Rautava ${ }^{5,6}$
}

To cite: Kytö V, Sipilä J, Rautava P. Gender-specific and age-specific differences in unstable angina pectoris admissions: a populationbased registry study in Finland. BMJ Open 2015;5: e009025. doi:10.1136/ bmjopen-2015-009025

- Prepublication history for this paper is available online. To view these files please visit the journal online (http://dx.doi.org/10.1136/ bmjopen-2015-009025).

Received 9 June 2015 Accepted 21 August 2015

\section{CrossMark}

${ }^{1}$ Heart Center, Turku University Hospital, Turku, Finland

2Department of Medicine, Research Centre of Applied and Preventive Cardiovascular Medicine, University of Turku, Turku, Finland

${ }^{3}$ Division of Clinical

Neurosciences, Neurology,

Turku University Hospital,

Turku, Finland

${ }^{4}$ Department of Neurology,

University of Turku, Turku,

Finland

${ }^{5}$ Clinical Research Center,

Turku University Hospital,

Turku, Finland

${ }^{6}$ Department of Public Health, University of Turku, Turku, Finland

Correspondence to Dr Ville Kytö; ville.kyto@utu.fi

\section{ABSTRACT}

Objective: To evaluate gender-specific and agespecific differences in the occurrence of unstable angina pectoris (UAP) caused admissions.

Design: Population-based retrospective registry study in Finland.

Participants: All consecutive patients aged $\geq 30$ years hospitalised with a primary diagnosis of UAP in 22 hospitals with a coronary catheterisation laboratory during 5/2000-10/2009.

Primary outcome measures: Gender-specific and age-specific differences and trends in occurrence of UAP admissions.

Results: The study period included 27282 admissions caused primarily by UAP. Of these, $61.9 \%$ occurred to men and $38.1 \%$ to women with age-adjusted relative risk (RR) of 1.85 (Cl 1.61 to 2.14) for the male gender $(p<0.0001)$. The standardised incidence rate of UAP during the whole study was 92.8 ( $\mathrm{Cl} 91.8$ to 93.9 )/ 100000 person-years. The incidence rate increased gradually from 1.3 in the population aged $30-34$ years to $268.0 / 100000$ in the population aged $75-84$ years. Men had a 2.4-fold risk for UAP admission compared with women in the general population (incidence rate ratio $2.39 ; \mathrm{Cl} 2.24$ to $2.56 ; p<0.0001$ ). Gender difference was present in all age groups. UAP caused $22.4 \%$ of acute coronary syndrome admissions and $4.7 \%$ of all cardiovascular admissions. UAP was more likely to be the cause of cardiovascular admission in male patients (RR=1.25; $\mathrm{Cl} 1.21$ to $1.30, p<0.0001$ compared with female patients), but there was no gender difference in acute coronary syndrome admissions. The incidence rate of UAP hospitalisations in the general population declined by an estimated $8 \%$ per study-year $(p<0.0001)$. Declining incidence was evident regardless of gender and age.

Conclusions: Men have a 2.4-fold overall RR for UAP admission compared to women in the general population. Admissions due to UAP have a declining incidence trend across the adult Finnish population.

\section{INTRODUCTION}

Acute coronary syndrome (ACS) is a major cause of cardiovascular morbidity and

\section{Strengths and limitations of this study}

- Characterises differences in the occurrence of unstable angina pectoris (UAP) caused admissions in different segments of the general population.

- Large-scale nationwide study using obligatory and controlled registry data from hospitals with a coronary catherisation laboratory.

- Diagnosis of UAP was done by the treating physicians.

mortality in the adult population. ${ }^{1}$ ACS is divided into myocardial infarction (MI) or unstable angina pectoris (UAP). The epidemiology of MI in general and in the two subtypes, ST-segment elevation MI (STEMI) and non-ST-segment elevation MI (NSTEMI), has been described in a number of studies. ${ }^{2-11}$ Current knowledge on the occurrence of UAP at the population level and in different population segments is, however, much more limited. Men have a higher risk of MI than women and the incidence of MI increases progressively with ageing. ${ }^{5}{ }^{12}$ The incidence of MI has been declining in a majority of western countries during recent years. ${ }^{24} 71213$ Whether this is true also for UAP is, however, unknown. In order to further clarify the epidemiology of UAP, we studied gender and age differences and trends in UAP occurrence in the general population.

\section{METHODS}

Study patients

We studied the rate and trends of UAP caused admissions in patients aged $\geq 30$ years. Patients admitted to participating hospitals with UAP as the primary discharge diagnosis (International Statistical Classification of Diseases 10th Revision 
(ICD-10) codes I20.0X) were included in the study. Data were collected from the Finnish Care Register for Health Care, a nationwide obligatory and automatically collected data base containing discharge data of all hospital admissions in Finland. Admissions beginning between 1 May 2000 and 31 October 2009 in any of the 22 Finnish hospitals with a coronary catheterisation laboratory that were treating emergency coronary patients were included. In addition, corresponding data of all cardiovascular admissions (primary discharge diagnosis ICD-10 code in class I) and MI admissions (I21 and I22) were collected. Gender-matched and agematched population data of mainland Finland from the corresponding period (31 766839 person-years) were obtained from Statistics Finland.

\section{Statistical methods}

Data were analysed by using negative binomial regression modelling. When modelling the incidence rate and proportion from cardiovascular and ACS admissions, natural logarithms of the corresponding population or number of all cardiovascular/ACS admissions were used as offset parameters. Incidence rate calculations were standardised with the direct method using the European 2013 standard population. Scale variables are presented as the mean $\pm \mathrm{SD}$ or median with IQR as appropriate. Categorical variables are presented as the percentage, relative risk (RR) or incidence rate ratio (IRR) with $95 \%$ CIs as appropriate. Poisson distribution was assumed in counting CIs for count data. $p$ Values $<0.05$ were considered statistically significant. Statistical analyses were performed using SAS V.9.4 (SAS Institute Inc, Cary, North Carolina, USA).

\section{RESULTS}

Frequency

The study period included 27282 UAP admissions, of which $61.9 \%$ (CI $60.9 \%$ to $62.8 \%$ ) occurred to men and $38.1 \%$ (CI $37.4 \%$ to $38.9 \%$ ) to women. Overall, the age and study-year adjusted RR of a patient with UAP to be a male was 1.85 (CI 1.61 to $2.14, \mathrm{p}<0.0001$ ). The median age of patients with UAP was 70 years (IQR 61-77). Men with UAP were significantly younger than women (66.4 \pm 11.1 vs $72.3 \pm 10.8$ years, $\mathrm{p}<0.0001)$. The number of patients increased steadily with age up to 75 years followed by a steep decline in octogenarians and older (figure 1A). Although age distribution had a similar pattern in both genders, the number of UAP admissions reached its peak at an older age in women (figure 1B).

\section{Incidence rate}

The crude total incidence rate of UAP admissions in participating hospitals was 111.3 (CI 109.6 to 113.0)/ 100000 person-years. The standardised incidence rate was 92.8 (CI 91.8 to 93.9 )/100 000. Among the male population, the crude incidence rate was 111.3 (CI 109.6 to 113.0) and the standardised rate 132.3 (CI 130.5 to
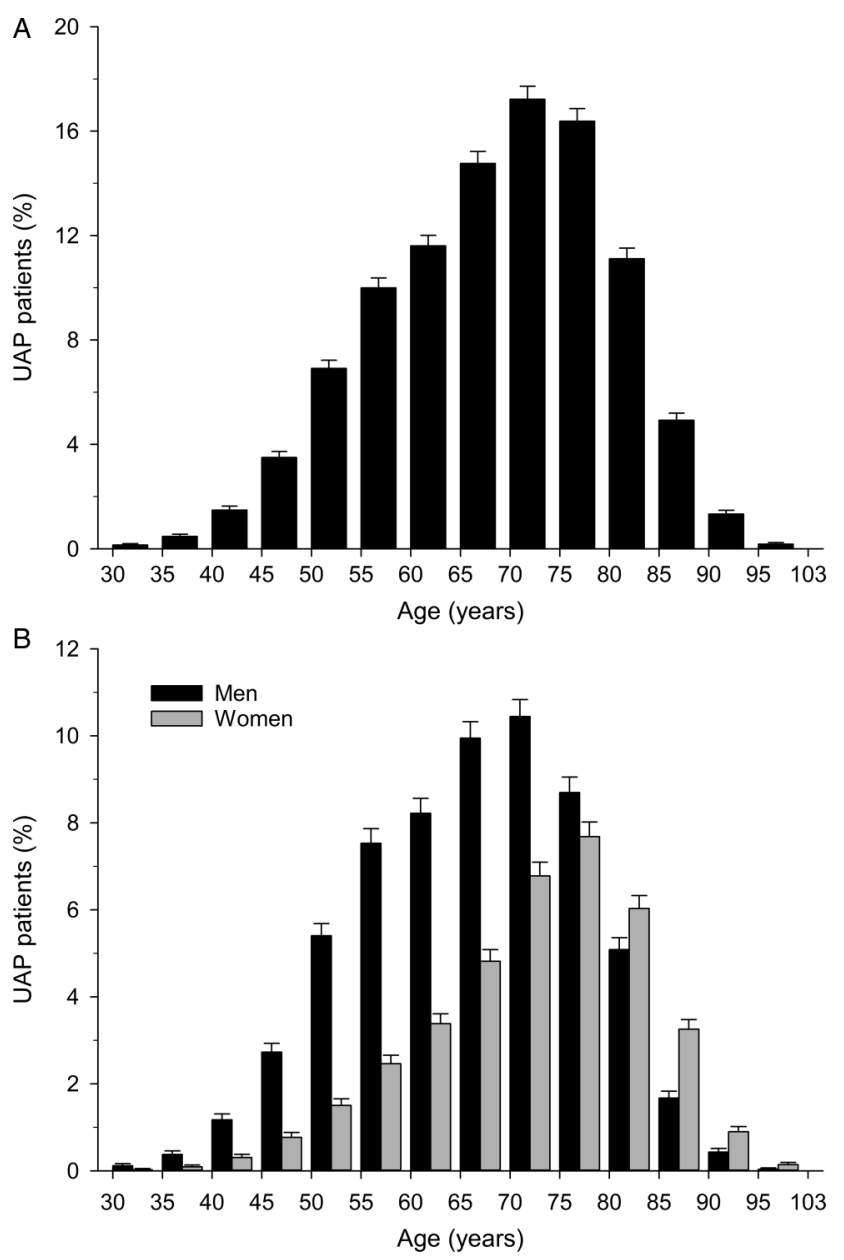

Figure 1 Frequency of unstable angina pectoris (UAP) admissions. Age distribution of all patients with $\operatorname{UAP}(A)$ and by gender (from the total number of patients) (B). Error bars represent upper limits of $95 \%$ Cls.

134.1)/100 000 while corresponding rates among the female population were 63.6 (CI 61.5 to 63.9 ) and 61.8 (CI 60.7 to 63.1 ), respectively. The total incidence rate increased gradually from 1.3 (CI 0.9 to 1.3 ) among the population aged $30-34$ years to 268.0 (CI 257.7 to 276.8)/100 000 among the general population aged 7584 years, followed by a decline in the older population (figure 2). The peak incidence in both genders occurred in the population aged 80-84 years (376.3; CI 356.7 to 396.6 in men and 214.6; CI 204.3 to 225.2 in women; figure 2B). Young men (30-39 years) had the highest RR for UAP admission compared to women (IRR 4.06; CI 2.76 to 5.94, $\mathrm{p}<0.0001$ ). Gender difference in IRR for UAP reduced with ageing, although men were at higher RR at all ages (figure 3). The overall age-adjusted and study-year adjusted IRR for UAP admission was 2.39 (CI 2.24 to 2.56) among men compared to women $(\mathrm{p}<0.0001)$.

\section{Annual trends}

The overall incidence rate of UAP admissions declined significantly during the study period from 135.7 

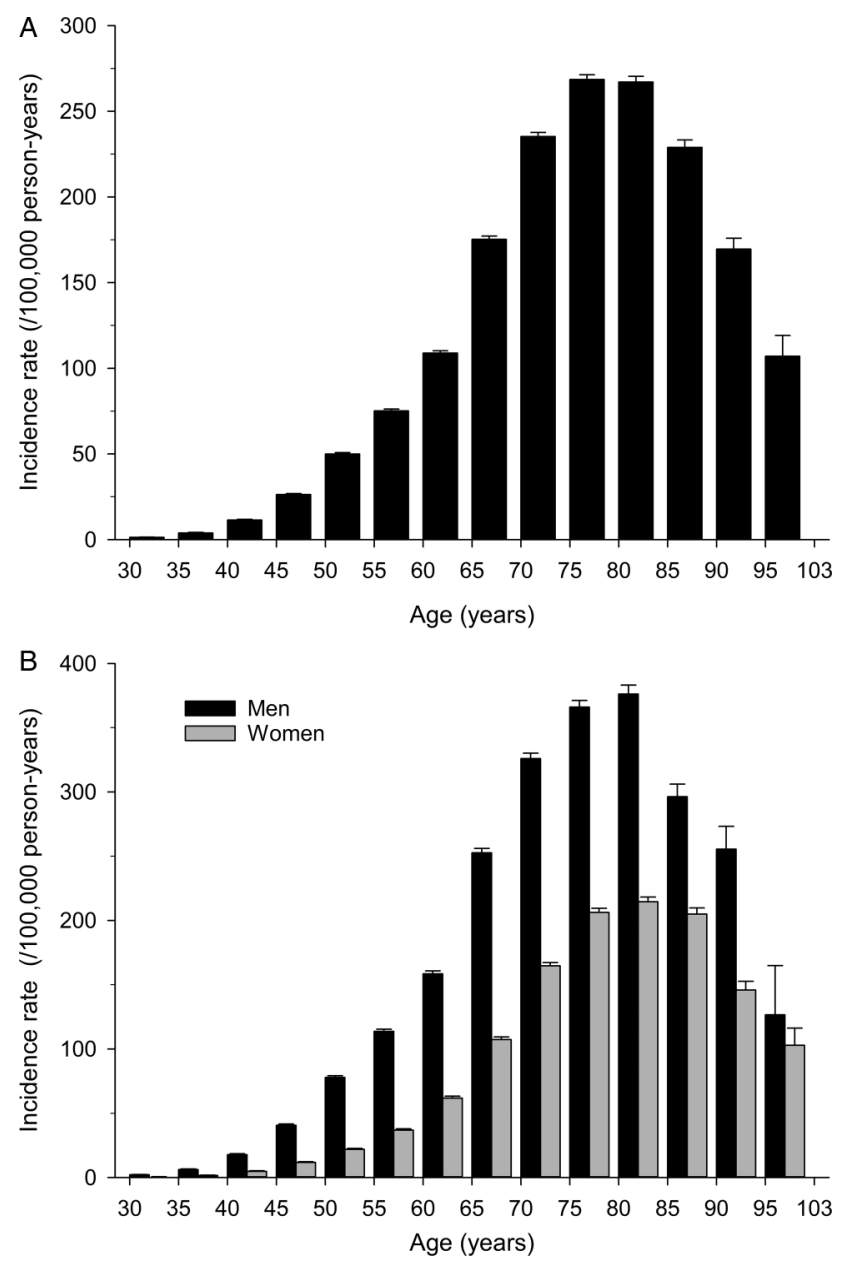

Figure 2 Incidence rate of unstable angina pectoris (UAP) admissions in the general population. Total $(A)$ and gender specific (B) incidence rates (per 100000 person-years) of UAP by age. Error bars represent upper limits of $95 \%$ Cls.

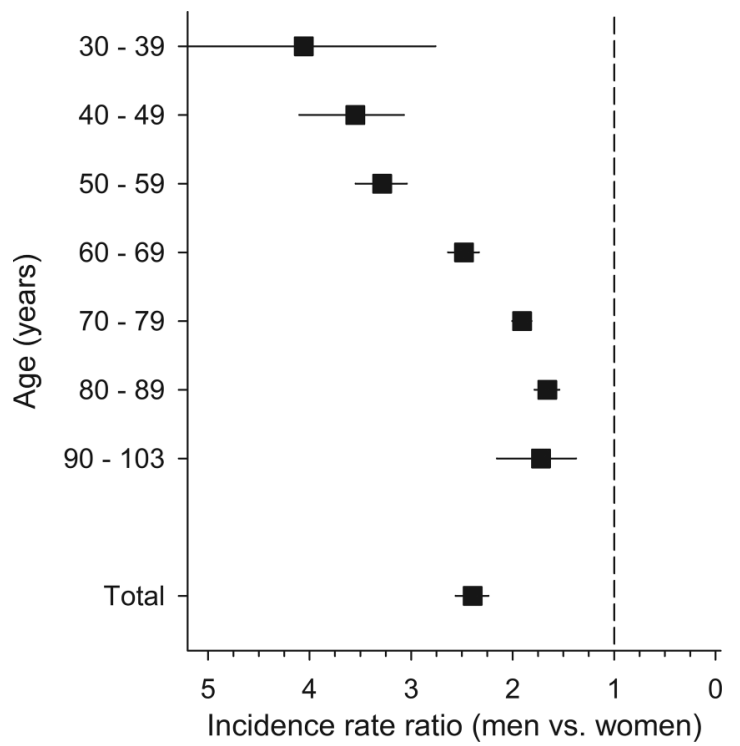

Figure 3 Gender-associated likelihood for unstable angina pectoris admissions in general population by age. The incidence rate ratio is calculated as men versus women and adjusted for study-year. Error bars represent $95 \%$ Cls.
(CI 130.9 to 140.7$) / 100000$ in 2000 to 63.9 (61.0 to $66.9) / 100000$ in 2009, with an estimated annual trend of $-8.0 \%(-9.0 \%$ to $-6.9 \%)$. The trend in UAP incidence was similarly declining in men and women (figure 4 and table 1). Incidence had a declining trend also in all age groups (figure 4). Although the largest absolute reduction in incidence of UAP was present in the oldest age groups, the percentual decrease was most prominent in patients aged $30-39$ years (table 1 ).

\section{Proportion of admissions}

UAP was the primary cause in $4.7 \%$ (CI $4.6 \%$ to $4.7 \%$ ) of all cardiovascular admissions. The proportion of UAP admissions increased gradually with ageing from $1.0 \%$ to $5.0 \%$ in patients aged 50-54 years (figure 5). In the patient population aged 50-74 years, the proportion of UAP admissions remained stable, followed by a gradual decrease to $2.1 \%$ in the oldest cardiovascular patients (figure 5A). In male cardiovascular patients, $5.1 \%$ (CI $5.0 \%$ to $5.1 \%$ ) of admissions were primarily due to UAP while a corresponding proportion was $4.1 \%$ (CI $4.0 \%$ to $4.1 \%$ ) in female patients. Overall, the RR for UAP admission was 1.25 (CI 1.21 to 1.30 ) among male
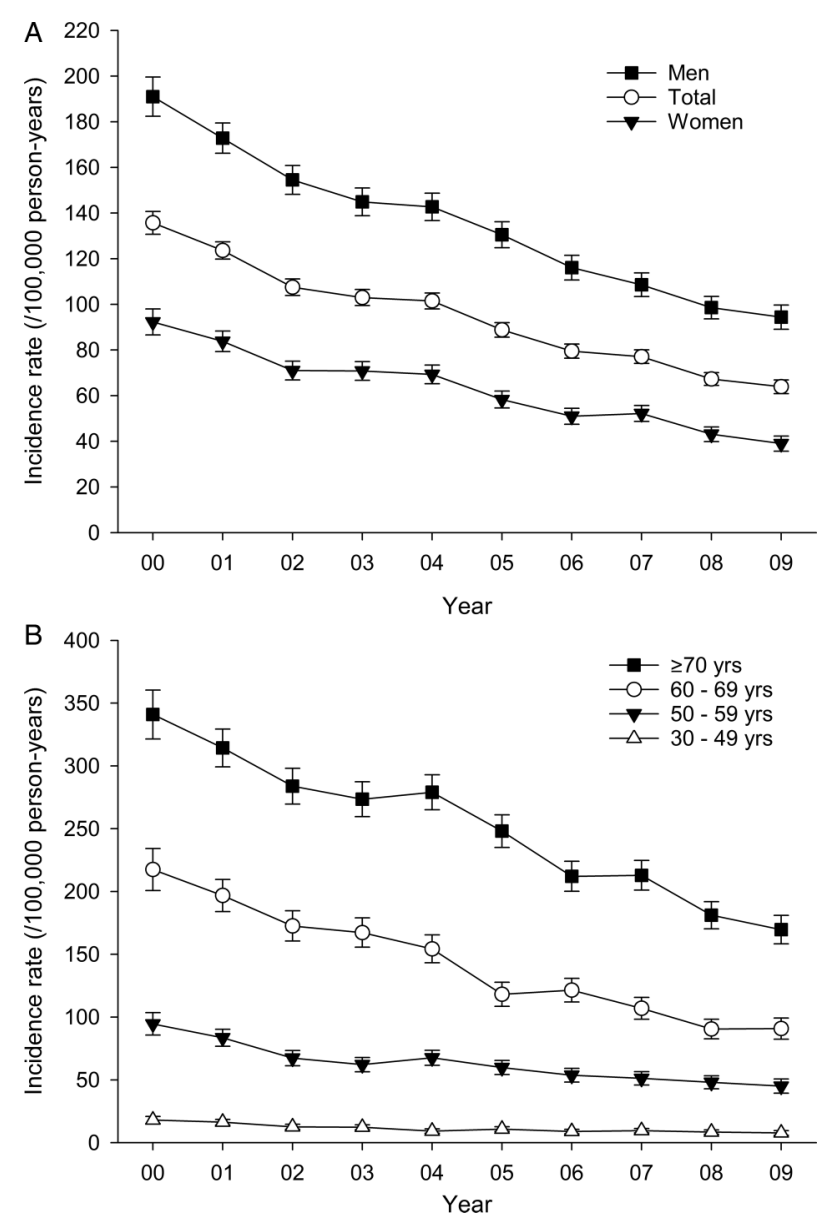

Figure 4 Annual trends for unstable angina pectoris admissions. Incidence rates are presented by gender $(A)$ and by age groups $(B)$. Total and gender-specific rates $(A)$ are standardised. Error bars represent $95 \%$ Cls. 
Table 1 Estimated annual incidence trends of unstable angina pectoris admissions in Finland during 2000-2009

\begin{tabular}{llrl}
\hline Group & Annual change (\%) & $\mathbf{9 5 \%} \mathbf{C l}(\%)$ & p Value \\
\hline $\begin{array}{l}\text { Total } \\
\text { Gender }\end{array}$ & -8.0 & -9.0 to -6.9 & $<0.0001$ \\
Men & -7.6 & -9.1 to -6.1 & $<0.0001$ \\
Women & -8.3 & -9.9 to -6.7 & $<0.0001$ \\
Age (years) & & & \\
30-39 & -12.6 & -17.5 to -7.4 & $<0.0001$ \\
$40-49$ & -7.8 & -9.9 to -5.6 & $<0.0001$ \\
$50-59$ & -8.0 & -9.1 to -6.8 & $<0.0001$ \\
$60-69$ & -9.6 & -10.5 to -8.6 & $<0.0001$ \\
$70-79$ & -8.4 & -9.2 to -7.5 & $<0.0001$ \\
$\geq 80$ & -5.6 & -5.6 to -4.4 & $<0.0001$ \\
\hline
\end{tabular}

cardiovascular patients compared to female patients $(\mathrm{p}<0.0001)$. Gender difference was more pronounced in the youngest patients, after which RR remained stable (figure 6). The gender difference in the risk of UAP was notably smaller among hospitalised cardiovascular patients (figure 6) than in the general population (figure 3).
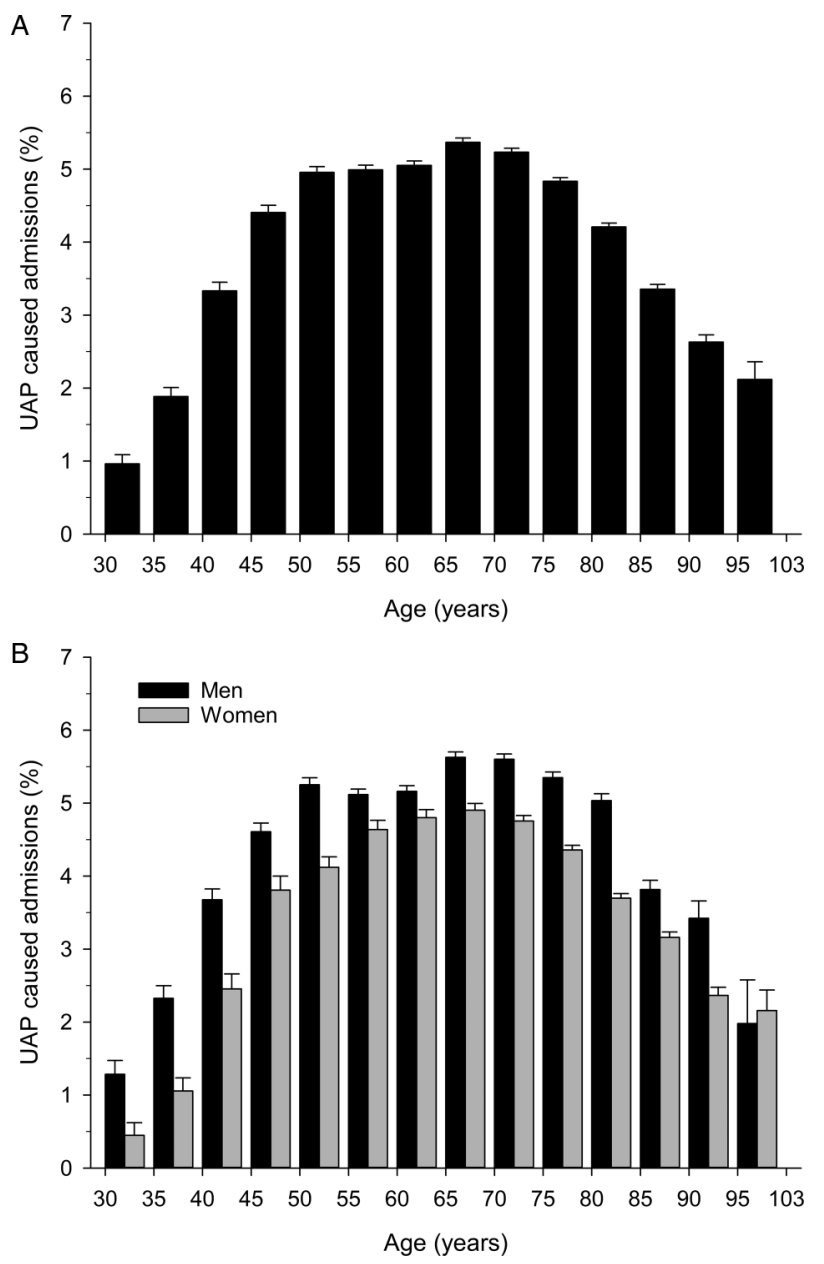

Figure 5 Proportion of cardiovascular admissions caused primarily by unstable angina pectoris. Total $(A)$ and gender-specific rates (\%) (B) by age. Error bars represent upper limits of $95 \%$ Cls.

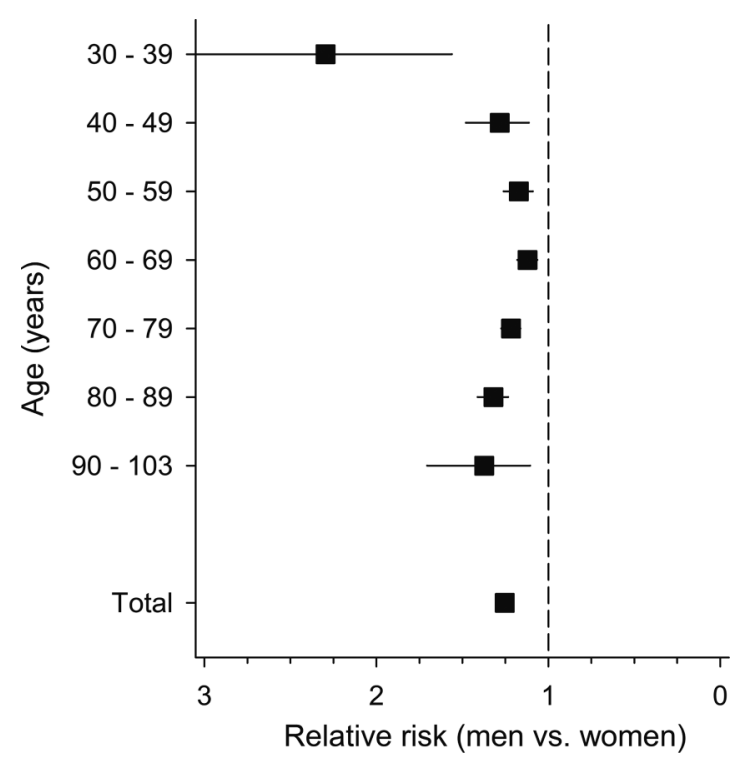

Figure 6 Gender-associated risk for unstable angina pectoris caused cardiovascular admission by age. Relative risk is calculated as men versus women and adjusted for study-year. Error bars represent $95 \%$ Cls.

Of all ACS admissions, $22.4 \%$ (CI $22.1 \%$ to $22.6 \%$ ) were caused by UAP. The proportion increased gradually from $18.1 \%$ in the youngest patients to $27.5 \%$ in patients aged $60-70$ years, followed by a steeper decline to $9.4 \%$ in non-agenarians and older (figure 7). ACS admission was due to UAP in $30 \%$ of patients in 2000 , but the proportion declined to $21.7 \%$ in 2003 while remaining more plateaued thereafter (figure 7). UAP caused $23.0 \%$ (CI $22.6 \%$ to $23.3 \%$ ) of ACS admissions among men and $21.5 \%$ (CI $21.1 \%$ to $21.9 \%$ ) in women, but after adjustment for age and study-year, there was no difference between genders $(p=0.14)$.

\section{DISCUSSION}

This multihospital study describes the occurrence of UAP admissions in different segments of the general population. Although epidemiology of MI has been explored in a number of studies, much less is known of UAP.

Men are known to have a higher risk of MI than women. ${ }^{5} 12$ However, data on potential gender differences regarding the occurrence of UAP have been scarce. A French registry of UAP admissions reported $71.2 \%$ of patients to be men, ${ }^{14}$ while in an Australian study the proportion was $60.2 \% .^{15}$ In smaller studies, male predominance in patients with UAP has ranged from $83.9 \%{ }^{16}$ to $56.6 \% .{ }^{17}$ Potential gender differences in the risk of UAP in the general population have not, however, to the best of our knowledge, been previously explored. We found $61.9 \%$ of patients to be men. Furthermore, men had a 2.4-fold overall risk for UAP admission in the general adult population compared to women. Curiously, this is exactly the same gender-based risk difference that was previously found for NSTEMI, ${ }^{12}$ 

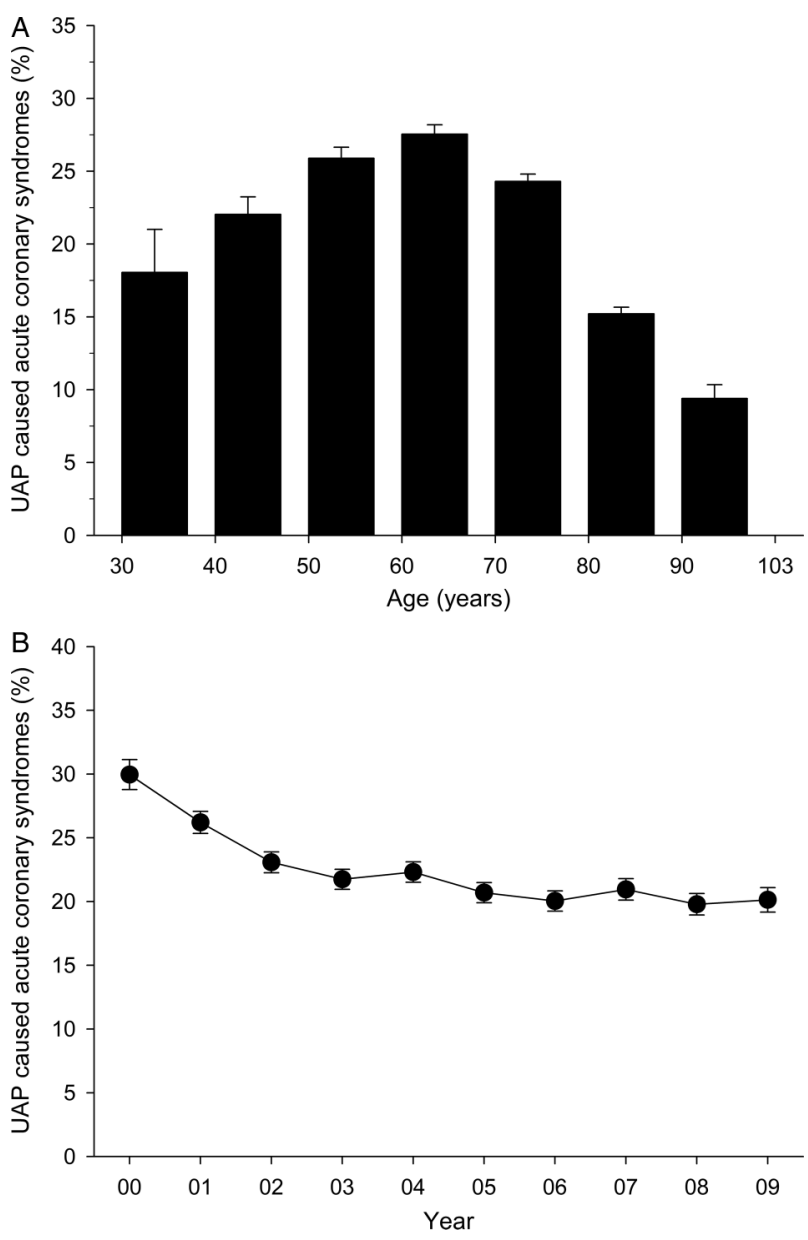

Figure 7 Proportion of unstable angina pectoris (UAP) within acute coronary syndrome admissions. UAP caused ACS admissions by age $(A)$ and by study-year $(B)$. Error bars represent $95 \%$ Cls.

while the RR for STEMI was $25 \%$ higher among men in the Finnish population. ${ }^{5}$ The gender bias in risk of UAP was most prominent in the youngest population in our study, and although gender difference was reduced with increasing age, men had a higher risk in all age groups. This is in line with a previous smaller Japanese study reporting more pronounced excess of men among UAP patients under 66 years of age. ${ }^{18}$ In addition, we found men to be more likely (1.3-fold) to have UAP as the cause of cardiovascular hospital admission than women. Although gender difference in the proportion of UAP caused cardiovascular admissions was less than found in the incidence, it was also present in all age groups. Within patients with ACS, however, we found no gender difference in the proportion of UAP caused admissions. Regional differences in the presentation of ACS seem, however, to be apparent, as UAP constitutes $45 \%$ of female patients and $23 \%$ of male patients with ACS in Middle Eastern countries. ${ }^{19}$

Previous studies have reported a mean age of 66-67 years for patients with UAP, ${ }^{14} 1718$ which is slightly less than 70 years found in our data. Female patients with UAP were on average 6 years older than male patients in our study population, comparably to previous findings in $\mathrm{UAP}^{15}$ and $\mathrm{MI}{ }^{12}$ The proportion of UAP within ACS admissions was, however, age dependent in our study population, as the proportion increased gradually to patients aged 60-70 years followed by a steep decline with increasing age. This result is likely to reflect age differences in the prevalence of stable coronary artery disease, ${ }^{1}$ but may also suggest potential agedependent differences in the pathophysiology of ACS. A decreasing proportion of UAP among ACS admissions in the elderly is likely to be affected by the study design, that is, only patients admitted to hospital were included.

The incidence of STEMI has been declining in a majority of Western countries during recent years, ${ }^{2} 42021$ while reports on the incidence trend of NSTEMI have been conflicting. ${ }^{2} 122022$ We found a significant $8 \%$ annual decline in UAP incidence in the general population. Notably, a declining trend was similar in both genders and across all age groups. Only a few previous studies have reported on trends of UAP incidence. In the USA, the incidence of UAP among Medicare beneficiaries has a declining trend comparable with that of our findings. ${ }^{23}$ In Western Australia, however, the decline in UAP admissions has been significantly slower ( $3 \%$ per annum) ${ }^{15}$

Our study is limited by the retrospective nature of administrative registry data. The general accuracy of a used nationwide, obligatory and automatic registry is, however, good ${ }^{24}$ and administrative hospital data have proved to be a reliable source of information on the occurrence of ACS. ${ }^{25} 26$ Diagnosis of UAP was made by treating doctors and data on used diagnostic tests such as troponin measurements were not available. In order to optimise the balance between diagnostic accuracy and representativeness of the study population, we included only patients who were admitted to a hospital with a coronary catherisation laboratory, thus excluding patients treated in smaller local hospitals. Overall, the incidence rates of UAP admissions found here are thus likely to underestimate the overall incidence rate of UAP, but are representative of patients considered to be in the scope of invasive treatments.

In conclusion, men have a 2.4-fold overall RR for UAP admission compared to women. Gender bias in UAP risk is highest among younger adults. UAP has a declining incidence trend across all segments of the adult Finnish population.

Contributors VK, JS and PR designed the study. VK and JS collected the data. VK conducted the analyses, all contributed to the interpretation of the results and VK drafted the manuscript. All authors accepted the final version of the manuscript.

Funding This work was financially supported by the Research Foundation of Turku University Hospital, Turku, Finland and the Finnish Cardiac Society, Oulu, Finland.

\section{Competing interests None declared.}

Ethics approval The study was approved by the National Institute for Health and Welfare (permission number THL/1576/5.05.00/2010). 
Provenance and peer review Not commissioned; externally peer reviewed.

Data sharing statement No additional data are available.

Open Access This is an Open Access article distributed in accordance with the Creative Commons Attribution Non Commercial (CC BY-NC 4.0) license, which permits others to distribute, remix, adapt, build upon this work noncommercially, and license their derivative works on different terms, provided the original work is properly cited and the use is non-commercial. See: http:// creativecommons.org/licenses/by-nc/4.0/

\section{REFERENCES}

1. Mozaffarian D, Benjamin EJ, Go AS, et al. Heart disease and stroke statistics-2015 update: a report from the American Heart Association. Circulation 2015;131:e29-322.

2. Yeh RW, Sidney S, Chandra M, et al. Population trends in the incidence and outcomes of acute myocardial infarction. $N$ Engl J Med 2010;362:2155-65.

3. Roger VL, Weston SA, Gerber Y, et al. Trends in incidence, severity, and outcome of hospitalized myocardial infarction. Circulation 2010;121:863-9.

4. Jennings SM, Bennett K, Lonergan M, et al. Trends in hospitalisation for acute myocardial infarction in Ireland, 1997-2008. Heart 2012;98:1285-9.

5. Kytö V, Sipilä J, Rautava P. Gender, age and risk for ST-elevation myocardial infarction. Eur J Clin Invest 2014;44:902-9.

6. Zhang Z, Fang J, Gillespie C, et al. Age-specific gender differences in in-hospital mortality by type of acute myocardial infarction. Am J Cardiol 2012;109:1097-103.

7. Smolina K, Wright FL, Rayner M, et al. Determinants of the decline in mortality from acute myocardial infarction in England between 2002 and 2010: linked national database study. BMJ 2012;344: d8059.

8. Laks T, Joeste E, Pullisaar O, et al. Trends in incidence, attack rate, and mortality of acute myocardial infarction in Estonia: the Tallinn AMI Registry 1991-2005. Ann Med 2013;45:107-11.

9. Radovanovic D, Nallamothu BK, Seifert B, et al. Temporal trends in treatment of ST-elevation myocardial infarction among men and women in Switzerland between 1997 and 2011. Eur Heart J Acute Cardiovasc Care 2012;1:183-91.

10. Radovanovic D, Erne P, Urban P, et al. Gender differences in management and outcomes in patients with acute coronary syndromes: results on 20,290 patients from the AMIS Plus Registry. Heart 2007;93:1369-75.

11. Coppieters $Y$, Collart $P$, Leveque A. Gender differences in acute myocardial infarction, twenty-five years registration. Int J Cardiol 2012;160:127-32.
12. Kytö V, Sipilä J, Rautava P. Association of age and gender with risk for non-ST-elevation myocardial infarction. Eur J Prev Cardiol 2015;22:1003-8.

13. Chen J, Normand SL, Wang Y, et al. Recent declines in hospitalizations for acute myocardial infarction for Medicare fee-for-service beneficiaries: progress and continuing challenges. Circulation 2010;121:1322-8.

14. Donataccio MP, Puymirat E, Vassanelli C, et al. Presentation and revascularization patterns of patients admitted for acute coronary syndromes in France between 2004 and 2008 (from the National Observational Study of Diagnostic and Interventional Cardiac Catheterization [ONACI]). Am J Cardiol 2014;113:243-8.

15. Nedkoff LJ, Briffa TG, Preen DB, et al. Age- and sex-specific trends in the incidence of hospitalized acute coronary syndromes in Western Australia. Circ Cardiovasc Qual Outcomes 2011;4:557-64.

16. Meune C, Balmelli C, Twerenbold R, et al. Patients with acute coronary syndrome and normal high-sensitivity troponin. Am J Med 2011;124:1151-7.

17. Manemann SM, Gerber Y, Chamberlain AM, et al. Acute coronary syndromes in the community. Mayo Clin Proc 2015;90:597-605.

18. Hoshida S, Hayashi T, Kanamasa K, et al. Comparison of risk factors in acute myocardial infarction and unstable angina pectoris in patients $<$ or $=66$ versus $>66$ years of age. Am J Cardiol 2004;93:608-10.

19. El-Menyar A, Zubaid M, Rashed W, et al. Comparison of men and women with acute coronary syndrome in six Middle Eastern countries. Am J Cardiol 2009;104:1018-22.

20. McManus DD, Gore J, Yarzebski J, et al. Recent trends in the incidence, treatment, and outcomes of patients with STEMI and NSTEMI. Am J Med 2011;124:40-7.

21. Ortolani $P$, Marino M, Melandri $G$, et al. Recent temporal trends for first-time hospitalization for acute myocardial infarction. Treatment patterns and clinical outcome in a large cohort study. Am Heart $J$ 2013;166:846-54

22. Wong CX, Sun MT, Lau DH, et al. Nationwide trends in the incidence of acute myocardial infarction in Australia, 1993-2010. Am J Cardiol 2013;112:169-73.

23. Shroff GR, Heubner BM, Herzog CA. Incidence of acute coronary syndrome in the general Medicare population, 1992 to 2009: a real-world perspective. JAMA Intern Med 2014;174:1689-90.

24. Sund R. Quality of the Finnish Hospital Discharge Register: a systematic review. Scand J Public Health 2012;40:505-15.

25. Nielsen KM, Foldspang A, Larsen ML, et al. Estimating the incidence of the acute coronary syndrome: data from a Danish cohort of 138290 persons. Eur J Cardiovasc Prev Rehabil 2007; 14:608-14.

26. Salomaa V, Havulinna AS, Koukkunen $\mathrm{H}$, et al. Aging of the population may not lead to an increase in the numbers of acute coronary events: a community surveillance study and modelled forecast of the future. Heart 2013;99:954-9. 